\title{
A crise hídrica como reflexo da seca: o Nordeste Setentrional em alerta.
}

\author{
The water crisis as reflection drought: the Northern Northeast in alert.
}

\author{
BEZERRA $^{1}$, M. B.; BEZERRA ${ }^{2}$, A. P. P. S. \\ marciobentolira@gmail.com;
}

\begin{abstract}
Resumo
A região Nordeste brasileira tem vivenciado uma das piores secas já registradas nos últimos anos. O presente trabalho tem como objetivo, realizar uma análise acerca da intensidade deste fenômeno, norteado mediante consulta aos níveis pluviométricos registrados nos últimos meses, de modo a apreciar os volumes hidrológicos totais e os armazenados nos reservatórios monitorados pela Agência Nacional das Águas na área objeto deste estudo. De modo a obter tais desígnios, tornou-se necessário a utilização de métodos e técnicas essenciais ao pleno desenvolvimento do trabalho investigativo, dos quais destacam-se o método de abordagem indutivo e o método de procedimento estatístico, bem como, o uso de técnicas de pesquisa constituídas pelas documentações indireta e direta intensiva. Como resultados destacamos os baixos níveis dos recursos armazenados responsáveis pela garantia hídrica da região, fenômeno decorrente dos baixos índices pluviométricos, característicos do longo período de estiagem que assola a região Nordeste do Brasil. Assim, considera-se a necessidade de políticas emergências, das quais objetivem suprir o anseio e a necessidade não só da população, mas de todo ecossistema.
\end{abstract}

Palavras-chave: Nordeste Setentrional. Fenômeno da seca. Crise hídrica.

\begin{abstract}
The Brazilian Northeast has experienced one of the worst droughts ever recorded in recent years. This study aims, conduct an analysis of the intensity of this phenomenon, guided by consultation with rainfall levels recorded in recent months in order to assess the total hydrological volumes and stored in reservoirs monitored by the Agência Nacional das Águas in the area subject of this study. In order to obtain such designs, it has become necessary to use methods and techniques essential to the full development of investigative work, of which we highlight the inductive method of approach and the method of statistical procedure, as well as the use of techniques research constituted by intensive direct and indirect documentation. The results highlight the low levels of stored resources responsible for water security in the region, a phenomenon due to the low rainfall, characteristic of the long period of drought plaguing the Northeast region of Brazil. Thus, it considers the need for emergency policies, which objectify meet the desire and the need not only the population, but the whole ecosystem.
\end{abstract}

Keywords: North Northeast. Phenomenon of drought. Water crisis

\section{INTRODUÇÃO}

Historicamente, a região Nordeste é reconhecida como a área mais propensa a longos períodos de estiagem, fenômeno este responsável por infortúnios que afetam o meio ambiente e a sociedade. Sua ocorrência é, em suma, caracterizada pelo atraso na precipitação das chuvas ou pela sua ocorrência abaixo do valor mínimo necessário à sobrevivência do ecossistema e é provocada tanto por fatores climáticos (latitude, altitude, continentalidade e maritimidade, massas de ar e correntes marítimas), como por fatores antrópicos (desmatamento e emissão de gases causadores do efeito estufa).

Como um fenômeno natural e cíclico, a seca, associada a degradação ambiental, é a responsável pela descaracterização física e social de uma determinada área. Ao manifestar-se com intensidades 
diferentes e dependendo do índice de precipitações pluviométricas, a seca pode ser considerada como absoluta (GASPAR, 2009), porém, dependerá da deficiência acentuada na quantidade de chuvas no ano, neste caso, inferior ao mínimo necessitado para manutenção do ecossistema.

O déficit pluviométrico ocorre mediante a interação dos fatores climáticos e antrópicos. As altas temperaturas, característica peculiar da região Nordeste, resultam num aumento considerável dos índices de evapotranspiração. Este fenômeno é extremamente importante, pois condiciona o balanço hídrico de uma determinada região e afeta o rendimento das bacias hidrográficas e a capacidade de armazenamento dos reservatórios nelas existentes.

A partir destas considerações, buscou-se no decorrer da pesquisa, analisar a ocorrência deste fenômeno na área compreendente a porção Setentrional da região Nordeste, de modo a promover o diagnóstico frente aos efeitos decorrentes do atual período de estiagem e o consequente déficit de disponibilidade hídrica. Para isto, considerando o período de chuvas na região que ocorre entre os meses de janeiro e maio, o acompanhamento desenvolvido pelos órgãos de monitoramento e gerenciamento pertencentes ao Governo Federal foram de extrema importância para a apresentação dos dados apresentados neste trabalho.

\section{METODOLOGIA}

Buscando alcançar os objetivos propostos, tornou-se necessário o emprego de métodos e técnicas especificas, classificadas como etapas concretas do processo investigativo. Os métodos, em suma, situam-se mediante a inspiração e o grau de abstração desenvolvido, distinguindo-se através das etapas da investigação, dispostas aqui como métodos de abordagem e métodos de procedimento. As técnicas, neste viés, compreendem-se como um conjunto de normas ou procedimentos responsáveis pela maneira na qual se delineará o procedimento investigativo, isto é, o meio pelo qual se desenvolverá a pesquisa.

De maneira sistêmica e racional, optou-se por empregar nesta pesquisa o método de abordagem indutivo, que segundo Marconi e Lakatos (2003, p. 106), caracteriza-se como um processo no qual a aproximação dos fenômenos parte-se de dados particulares, suficientemente constatados e cada vez mais abrangente, caracterizado pela inferência das constatações mais particulares, de maneira ascendente, às leis e teorias. Para tal, considerou-se alguns elementos fundamentais, como a observação dos fenômenos, a descoberta da relação existentes entre eles e a generalização das relações existentes.

De mesmo modo, buscando complementar a proposta estabelecida, empregou-se o método de procedimento estatístico, que, conforme Marconi e Lakatos (2003, p. 108), é o processo responsável 
pelo fornecimento de descrições quantitativas, das quais permitem comprovar as relações dos fenômenos entre si, sua natureza, ocorrência ou significado.

Já as técnicas, considerando suas especificidades e visando a obtenção dos propósitos, delimitam-se no desenvolver do processo investigativo pela consulta as mais diversas fontes existentes. Assim, seguindo as fundamentações explicitadas em Marconi e Lakatos (2003, p. 174195), optou-se no desenvolver da pesquisa pelo emprego das documentações: a) indireta, caracterizada pelas pesquisas documental (fontes estatísticas) e bibliográfica (materiais cartográficos e publicações diversas); e, b) direta intensiva, realizada através do processo de observação assistemática, não-participante, individual e em ambiente real.

\section{RESULTADOS E DISCUSSÃO}

A região Nordeste brasileira tem nos últimos anos sofrido o reflexo dos baixos índices pluviométricos, principalmente, na porção correspondente a região semiárida. As baixas precipitações têm proporcionado uma situação considerada como crítica, influenciando diretamente na disponibilidade hídrica, isto é, os níveis dos reservatórios, responsáveis pelo armazenamento de parte das águas superficiais destinadas aos múltiplos usos estabelecidos pelos poderes outorgantes tornaram-se escassos, com níveis abaixo da normalidade.

Na ilustração a seguir é apresentada a precipitação média anual registrada a partir de dados fornecidos pela rede hidrometeorológica nacional na área correspondente a porção Setentrional da região Nordeste, na qual apresenta variação entre 400 e 1900 mm/ano. Contudo, como observado, verifica-se uma variabilidade espacial dos índices pluviométricos oscilando entre 400 e $800 \mathrm{~mm} / \mathrm{ano}$ na maior parte do território, limitada a fração correspondente a região semiárida (CPRM, 2011).

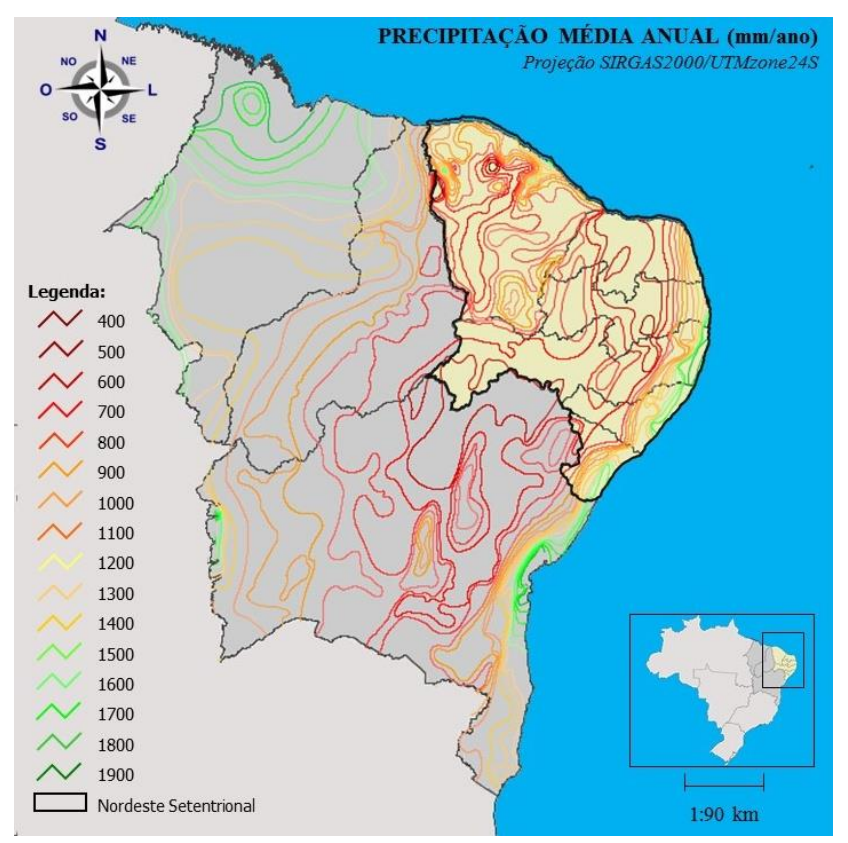


Figura 01. Precipitação média anual registrada na região Nordeste. Período de referência: 1977-2006. Fonte: Elaborado por Bezerra (2016); Base de dados shapefiles: CPRM (2011).

Com uma área de aproximadamente $406.009 \mathrm{~km}^{2}$, o Nordeste Setentrional corresponde a pouc o mais de $26 \%$ da região Nordeste, e abrange os Estados do Ceará, Pernambuco, Paraíba, Rio Grande do Norte, Alagoas e Sergipe. Quando considerado a capacidade de seu sistema hídrico, o Nordeste Setentrional é o responsável pelo armazenamento de 86,7\% das águas disponíveis nos reservatórios monitorados pela Agência Nacional das Águas (ANA).

Em números, são 534 reservatórios distribuídos entre os nove Estados da região Nordeste, responsáveis por armazenar $37.560,95 \mathrm{hm}^{3}$ (figura 02). Na área correspondente ao Nordeste Setentrional, conforme dados da ANA (2016a), são 463 reservatórios com capacidade de armazenamento de $30.376,71 \mathrm{hm}^{3}$.

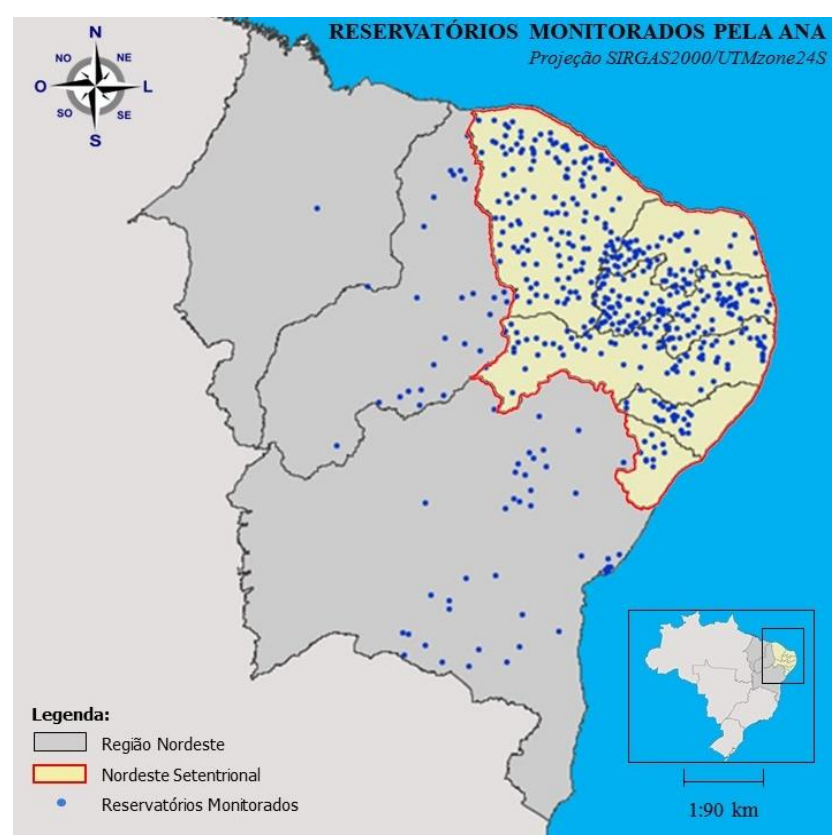

Figura 02. Reservatórios monitorados pela ANA na região Nordeste. Fonte: Elaborado por Bezerra (2016); Base de dados shapefiles: ANA (2016a).

Entretanto, devido aos baixos índices pluviométricos registrados nos últimos anos, os níveis desses reservatórios têm sido drasticamente reduzidos, comprometendo, como mencionado, os múltiplos usos (consumo humano, dessedentação animal, irrigação e aquicultura). Cabe ressaltar ainda, podendo ser observado ao compararmos as figuras 01 e 02 , que na área detentora dos menores índices pluviométricos é onde estão localizados a maioria dos reservatórios responsáveis pela demanda hídrica da porção Setentrional nordestina.

Nesta área encontramos grandes reservatórios construídos estrategicamente pelo Departamento Nacional de Obras Contra as Secas (DNOCS), uma autarquia federal responsável pela execução de obras de proteção contra as secas e inundações, dos quais destacamos: o Açude Castanhão (6.700 hm³), Orós (1.940 hm³) e Banabuiú (1.601 hm³), no Estado do Ceará; os Açudes Curemas e Mãe 
D’água, que interligados constituem o Sistema Curemas-Mãe D’água (1.159 hm³), no Estado da Paraíba; e o Açude Engenheiro Armando Ribeiro Gonçalves (2.400 hm³), no Estado do Rio Grande do Norte (ANA, 2016c).

$\mathrm{Na}$ tabela a seguir, encontra-se disposto o panorama acerca da quantidade de reservatórios monitorados, a capacidade total de armazenamento e os volumes parciais registrados em cada Estado da região Nordeste, inclusive, a equivalência percentual em relação a quantidade, capacidade e volume atual dos reservatórios.

Tabela 01. Volume dos reservatórios da região Nordeste, por Estado, monitorados pela Agência Nacional das Águas. Mês de referência - julho/2016. Fonte: ANA (2016a).

\begin{tabular}{c|c|c|c|c|c|c}
\hline \multicolumn{7}{c}{ Volume dos reservatórios, total e parcial, por Estado em $\mathbf{~ h m}^{\mathbf{3}}$} \\
\hline Estados & Reservatórios & $\mathbf{\%}$ & Capacidade & $\mathbf{\%}$ & Vol. Parcial & $\mathbf{\%}^{\mathbf{1}}$ \\
\hline Ceará & 151 & 28,28 & $18.824,14$ & 50,12 & $2.264,16$ & 12,02 \\
\hline Rio Grande do Norte & 56 & 10,49 & $4.536,67$ & 12,08 & 946,84 & 20,87 \\
\hline Bahia & 45 & 8,43 & $4.404,97$ & 11,73 & $2.620,08$ & 59,48 \\
\hline Paraíba & 123 & 23,03 & $3.737,79$ & 9,95 & 603,67 & 16,15 \\
\hline Pernambuco & 101 & 18,91 & $3.198,61$ & 8,51 & 408,19 & 12,76 \\
\hline Piauí & 25 & 4,68 & $1.765,27$ & 4,7 & 980,92 & 55,56 \\
\hline Maranhão & 1 & 0,19 & $1.014,00$ & 2,7 & 620,00 & 61,14 \\
\hline Alagoas & 22 & 4,12 & 60,15 & 0,16 & 29,16 & 48,47 \\
\hline Sergipe & 10 & 1,87 & 19,35 & 0,05 & 10,66 & 55,09 \\
\hline Total & $\mathbf{5 3 4}$ & $\mathbf{1 0 0 , 0 0}$ & $\mathbf{3 7 . 5 6 0 , 9 5}$ & $\mathbf{1 0 0 , 0 0}$ & $\mathbf{8 . 4 8 3 , 6 8}$ & $\mathbf{2 2 , 5 8}$ \\
\hline
\end{tabular}

Mediante exposição destes dados, observa-se a disparidade existente entre os nove Estados pertencentes a região Nordeste no tocante a quantidade de reservatórios e a capacidade total de armazenamento. Esta desigualdade torna-se ainda mais perceptível quando comparado à população absoluta em cada Estado.

Tabela 02. Disparidades diagnosticadas a partir da análise dos volumes dos reservatórios da região Nordeste, por Estado. Mês de referência - julho/2016. Fonte: ANA (2016a); IBGE (2016).

\begin{tabular}{c|c|c|c|c}
\hline \multicolumn{5}{c}{ Comparativo entre os Estados da região Nordeste e sua população absoluta } \\
\hline Estados & Habitantes $^{\mathbf{2}}$ & Reservatórios & Capacidade $\left.\mathbf{( h m}^{\mathbf{3}}\right)$ & $\mathbf{~ h m}^{\mathbf{3} / \mathbf{h a b i t a n t e}}$ \\
\hline Ceará & 8.904 .459 & 151 & $18.824,14$ & 0,0021 \\
\hline Rio Grande do Norte & 3.442 .175 & 56 & $4.536,67$ & 0,0013 \\
\hline Bahia & 15.203 .934 & 45 & $4.404,97$ & 0,0002 \\
\hline Paraíba & 3.972 .202 & 123 & $3.737,79$ & 0,0009 \\
\hline Pernambuco & 9.345 .173 & 101 & $3.198,61$ & 0,0003 \\
\hline Piauí & 3.204 .028 & 25 & $1.765,27$ & 0,0005 \\
\hline Maranhão & 6.904 .241 & 1 & $1.014,00$ & 0,0001 \\
\hline Alagoas & 3.340 .932 & 22 & 60,15 & 18,0 \\
\hline Sergipe & 2.242 .937 & 10 & 19,35 & 8,6 \\
\hline Total & $\mathbf{5 6 . 5 6 0 . 0 8 1}$ & $\mathbf{5 3 4}$ & $\mathbf{3 7 . 5 6 0 , 9 5}$ & $\mathbf{0 , 0 0 0 6}$ \\
\hline
\end{tabular}

\footnotetext{
${ }^{1}$ Percentuais correspondentes ao volume atual dos reservatórios em relação a capacidade total de armazenamento.

${ }^{2}$ População estimada em 2015 conforme estabelecido pelo Instituto Brasileiro de Geografia e Estatística (IBGE).
} 
Em outro cenário, no qual se desassocia a porção Setentrional da região Nordeste do restante do território, pode ser observado à vulnerabilidade hídrica pela qual se encontra essa região. Quando comparadas, assim como na análise anterior, percebe-se a equivalência percentual em relação a quantidade, capacidade, volume atual dos reservatórios e consequente disparidade com relação a demanda volume/habitantes.

Tabela 03. Volume dos reservatórios da região Nordeste, por região, monitorados pela Agência Nacional das Águas. Mês de referência - julho/2016. Fonte: ANA (2016a).

\begin{tabular}{c|c|c|c|c|c|c}
\hline \multicolumn{7}{c}{ Volume dos reservatórios, total e parcial, por região em $\mathbf{~ h m}^{\mathbf{3}}$} \\
\hline Região & Reservatórios & $\mathbf{\%}$ & Capacidade & $\mathbf{\%}$ & Vol. Parcial & \% \\
\hline Nordeste Setentrional & 463 & 86,7 & $30.376,71$ & 80,87 & $4.262,68$ & 14,03 \\
\hline Bahia-Maranhão-Piauí & 71 & 13,3 & $7.184,24$ & 19,13 & $4.221,00$ & 58,75 \\
\hline Total & $\mathbf{5 3 4}$ & $\mathbf{1 0 0 , 0 0}$ & $\mathbf{3 7 . 5 6 0 , 9 5}$ & $\mathbf{1 0 0 , 0 0}$ & $\mathbf{8 . 4 8 3 , 6 8}$ & $\mathbf{2 2 , 5 8}$ \\
\hline
\end{tabular}

Tabela 04. Disparidades diagnosticadas a partir da análise dos volumes dos reservatórios da região Nordeste, por região. Mês de referência - julho/2016. Fonte: ANA (2016a); IBGE (2016).

\begin{tabular}{c|c|c|c|c}
\hline \multicolumn{6}{c}{ Comparativo entre os Estados da região Nordeste e sua população absoluta } \\
\hline Estados & Habitantes & Reservatórios & Capacidade (hm $\mathbf{h}^{\mathbf{3}}$ & $\mathbf{h m}^{\mathbf{3}} / \mathbf{h a b i t a n t e}$ \\
\hline Nordeste Setentrional & 31.247 .878 & 463 & $30.376,71$ & 0,0009 \\
\hline Bahia-Maranhão-Piauí & 25.312 .203 & 71 & $7.184,24$ & 0,0002 \\
\hline Total & $\mathbf{5 6 . 5 6 0 . 0 8 1}$ & $\mathbf{5 3 4}$ & $\mathbf{3 7 . 5 6 0 , 9 5}$ & $\mathbf{0 , 0 0 0 6}$ \\
\hline
\end{tabular}

Nota-se, ao compararmos as tabelas acima expostas, que a disponibilidade volume/habitante nos Estados da Bahia, Maranhão e Piauí são bem inferiores que a registrada entre os Estados localizados na porção Setentrional da região Nordeste. A disponibilidade hídrica total e atual dos reservatórios acompanhados demonstra a insuficiência deste recurso a partir da disparidade existente. Enquanto a porção Setentrional é a responsável por armazenar 80,87\% da capacidade total da região Nordeste, os Estados da Bahia, Maranhão e Piauí armazenam 19,13\% de capacidade restante. No entanto, considerando o volume atual armazenado, esse quadro inverte-se.

O consumo diferenciado se torna evidente ao tempo em que se registra a disponibilidade de $14,03 \%$ da capacidade total na porção Setentrional e de 58,75\% da capacidade total nos Estados da Bahia, Maranhão e Piauí. Um dos motivos responsáveis por esse diferencial de consumo ocorre em virtude de as águas armazenadas nos reservatórios do Nordeste Setentrional serem destinadas, juntos aos demais usos, a irrigação, atividade responsável por $72 \%$ do consumo de água no Brasil (ANA, 2013, p. 354). No restante da região Nordeste o consumo a partir desta atividade é reduzido em virtude dos usos estabelecidos junto aos reservatórios pertencentes ao sistema elétrico nacional, nos Estados da Bahia, Pernambuco, Piauí, Alagoas e Sergipe.

Deste modo, os dados dispostos nas tabelas 02 e 04 aqui servem como eixo norteador da situação de risco em que se encontra a área objeto desta pesquisa, onde, em suma, se registra a menor 
equivalência volume/habitante para a área de maior disponibilidade hídrica, mesmo, sendo esta, a área detentora do menor número de reservatórios e capacidade de armazenamento.

Os baixos níveis acumulados nestes reservatórios, como mencionado anteriormente, ocorrem devido aos baixos índices pluviométricos registrados nos últimos anos. Este déficit vem se agravando a cada ano motivados pelo efeito da seca nessa região, principalmente, nos Estado do Ceará, Rio Grande do Norte, Paraíba e Pernambuco.

Em um cenário no qual deve-se considerar a vazão afluente, a vazão defluente e os níveis de evaporação sobre o volume de água nos reservatórios destes Estados, mediante análise que tem como espaço de tempo o período 2012/2016, observa-se nos gráficos a seguir o declínio significativo nos volumes armazenados nos 463 mananciais situados no Nordeste Setentrional. Os gráficos expressam visualmente o panorama desolador provocado pela seca no território nordestino.
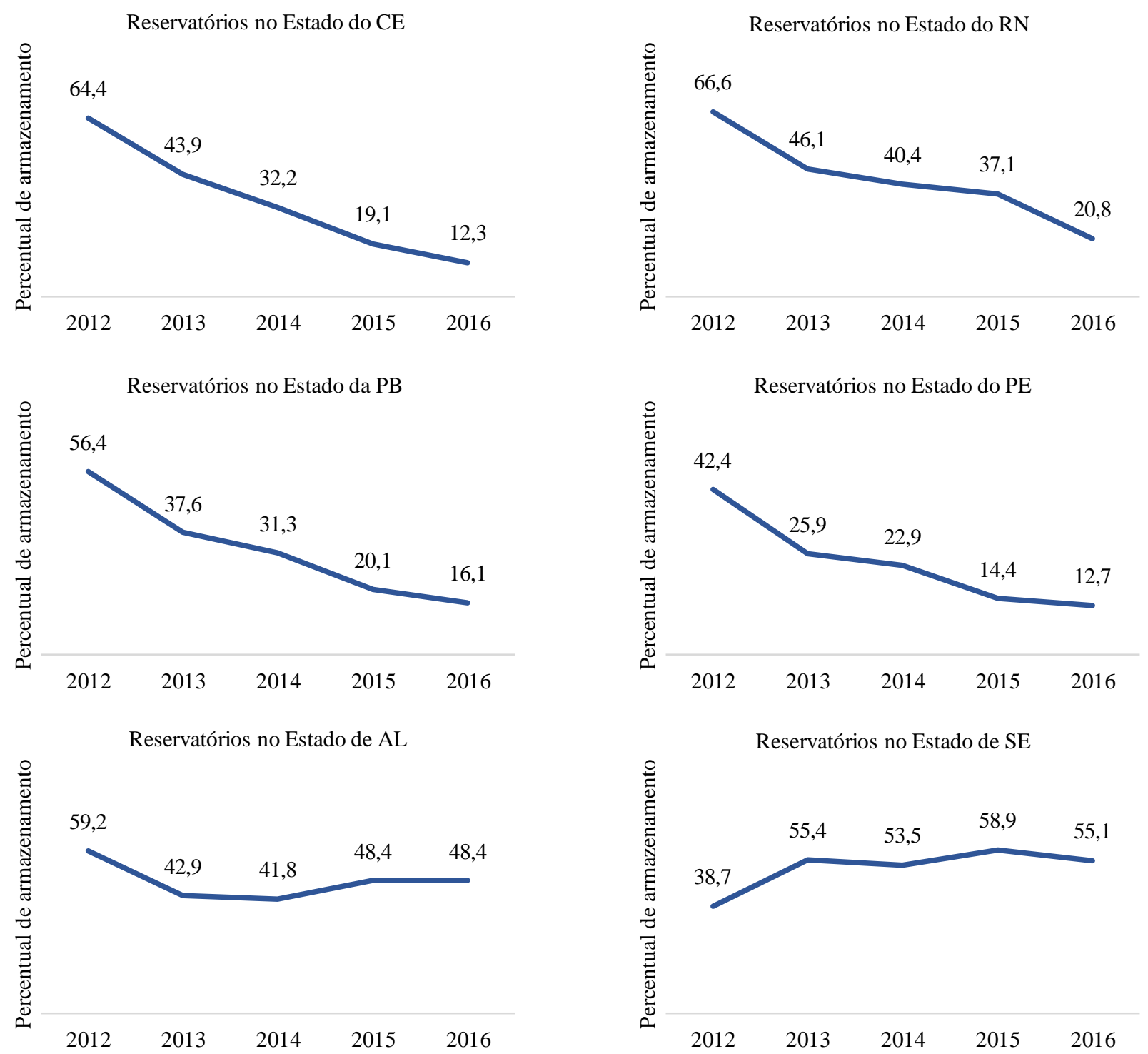

Figura 03. Gráficos da evolução dos percentuais de armazenamento dos reservatórios monitorados pela ANA, entre os anos de 2012 e 2016, nos Estados da porção Setentrional da região Nordeste. Fonte: Elaborado por Bezerra (2016). 
Consideramos de suma importância salientar que os dados obtidos, analisados e apresentados nas tabelas e gráficos, com relação aos volumes máximos e atuais de armazenamento dos reservatórios referem-se, como mencionado, aos construídos pelo DNOCS e monitorados pela ANA, destinados aos usos múltiplos, dispensando-se assim, os barramentos construídos pela Companhia Hidrelétrica do São Francisco (CHESF) e monitorados pelo Operador Nacional do Sistema Elétrico (ONS), dos quais destinam-se apenas a geração de energia, regularização, irrigação e navegação, são eles: os de Sobradinho, Piloto, Paulo Afonso I, II, III e IV, no Estado da Bahia; o de Boa Esperança, no Estado do Piauí; o Luiz Gonzaga, no Estado de Pernambuco; o Apolônio Sales, no Estado de Alagoas; e o Xingó, na divisa dos Estados de Alagoas e Sergipe.

Em meio a atual situação, os órgãos de monitoramento vinculados aos governos federal e estaduais atentam-se para possíveis desastres ambientais sem precedentes caso a estiagem que se perdura há alguns anos. Através do Sistema Integrado Sobre Desastres (S2ID), banco de dados disponibilizado pelo Ministério da Integração (MI), podemos observar nos gráficos a seguir, os eventos registrados na região Nordeste no atual período de estiagem e de seca (2012/2016).
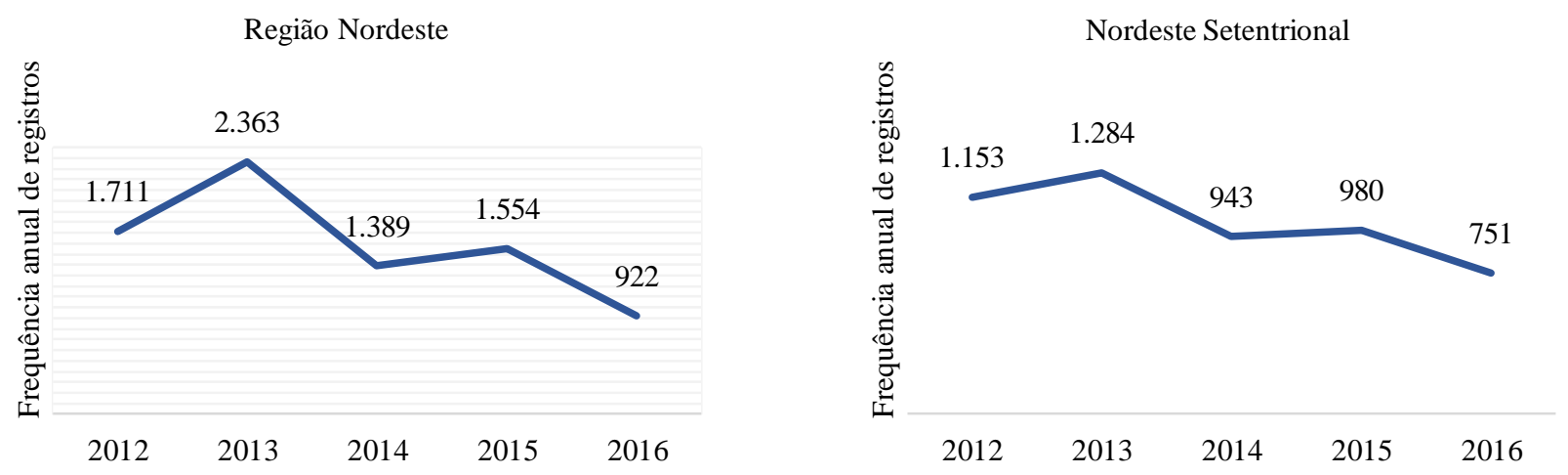

Figura 04. Gráficos da frequência anual de registros de estiagem e seca, com destaque aos municípios da região Nordeste e da porção Setentrional nordestina, entre os anos de 2012 e 2016. Fonte: Elaborado por Bezerra (2016).

O Ministério do Meio Ambiente (MMA), através da Secretaria de Recursos Hídricos, desenvolveu entre os anos de 2003 e 2004 uma série de estudos denominada de Programa de Ação Nacional de Combate à Desertificação e Mitigação dos Efeitos da Seca (PAN-Brasil). Este projeto teve como objetivo, promover a integralização de diversos setores públicos e privados (governos e sociedade), de modo a atender as demandas recorrentes de ações emergenciais contra os efeitos provocados pelo fenômeno da seca na região semiárida.

Considerando o disposto na Lei $\mathrm{n}^{\circ}$ 7.827/1989, que institui o Fundo Constitucional de Financiamento do Nordeste (FNE), responsável pela nova delimitação do polígono das secas, ora denominada região semiárida, observa-se que a maioria dos eventos registrados no período 
2012/2016, bem como, os menores índices pluviométricos e consequentes baixos níveis de armazenamento dos reservatórios, ocorrem na fração central do semiárido nordestino.

Este fragmento do território nordestino é caracterizado por sua variabilidade climática acentuada, mediante atuação da Zona de Convergência Intertropical (ZCTI), na qual a incidência dos períodos de estiagem e de secas acontecem com frequência, variando entre $81 \%$ e $100 \%$, sob influência de fenômenos climáticos como o El Niño, a La Niña e o Dipolo do Atlântico.

A partir de dados disponibilizados pelo MMA e pela ANA, representados na figura a seguir, é possível observar a espacialidade dessa incidência, assim como, seu nível de intensidade.
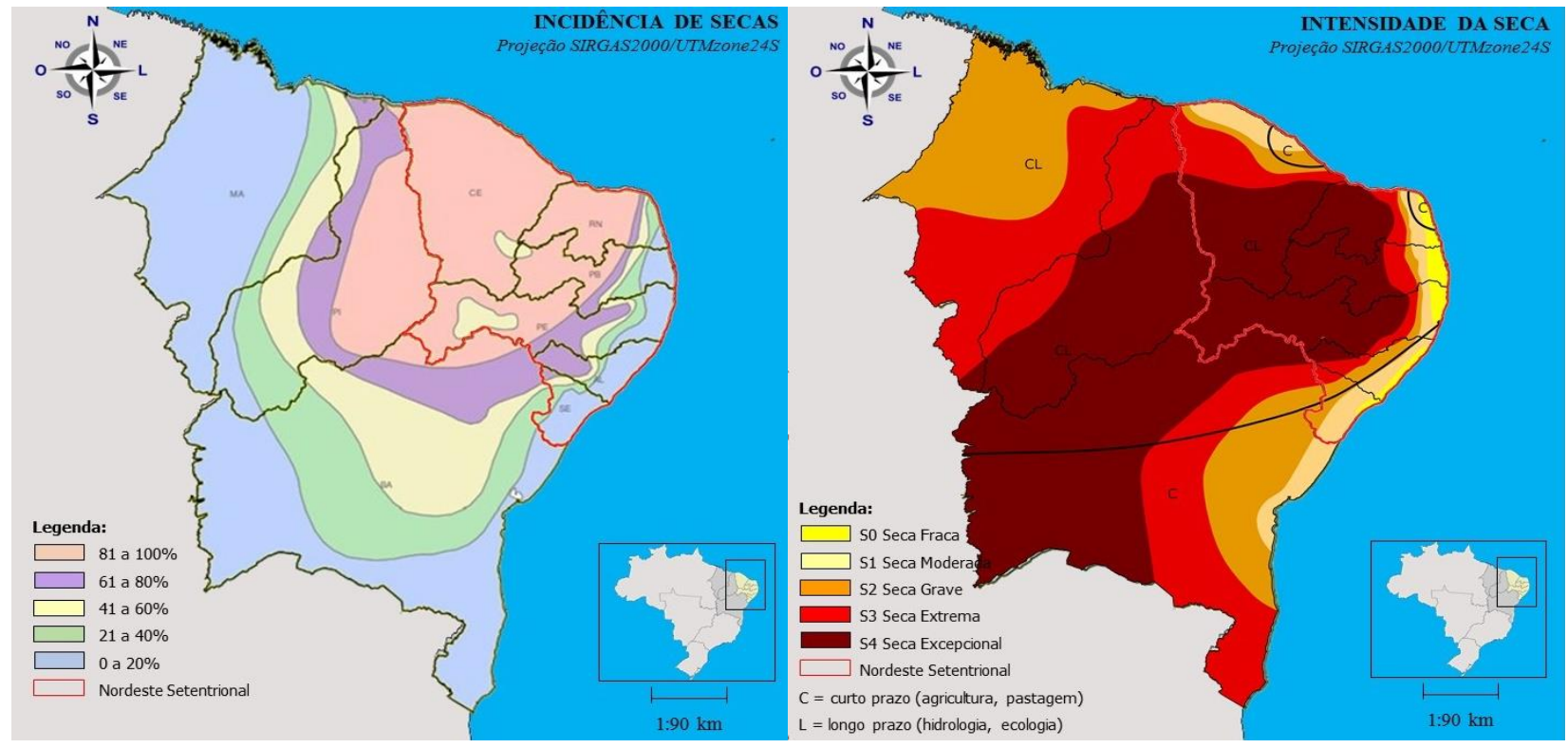

Figura 05. Percentual de suscetibilidade aos efeitos da seca e maior intensidade de seca registrada nos últimos doze meses na região Nordeste. Fonte: Elaborado por Bezerra (2016); Base de dados shapefiles: ANA (2016b).

O nível de intensidade a qual a figura representa foi registrado no mês de dezembro de 2015, sendo este o maior nível apresentado nos últimos dez meses, período correspondente ao intervalo decorrido do ano hidrológico 2015/2016, isto é, a estação ininterrupta de doze meses caracterizada pela ocorrência de um ciclo anual climático completo.

\section{CONSIDERAÇÕES FINAIS}

Como pôde ser observado, a incidência de secas na região Nordeste é intensa e, particularmente, afeta com maior ênfase a porção setentrional nordestina, entretanto, sua maior intensidade se expande, afetando drasticamente os limites desta fração do território. Este fenômeno proporciona o desenvolvimento de áreas consideradas como susceptíveis ao processo de desertificação, que de acordo com o PAN-Brasil, transcendente a delimitação semiárida, como expresso na figura correspondente a intensidade da seca. 
Em números, com base nos dados levantados pela ANA (2016b), o grau de intensidade e consequente comprometimento em mm/mês equivalem a: S0 - Seca fraca $=125 \mathrm{~mm}$; S1 - Seca moderada $=100 \mathrm{~mm} ; \mathrm{S} 2-$ Seca Grave $=75 \mathrm{~mm} ; \mathrm{S} 3$ - Seca extrema $=50 \mathrm{~mm} ; \mathrm{S} 4$ - Seca excepcional $=25 \mathrm{~mm}$. Outrossim, ambas as áreas mantém estreita relação quanto ao tempo de ocorrência, isto é, curto e longo prazo, responsáveis pela efetiva degradação do meio ambiente.

Embora não exista objetivamente como prever a reversão do atual quadro que se encontra a área delimitada para este estudo, cabe aqui aguardarmos o fim do atual ciclo hidrológico e, consequentemente, o início do próximo, para que assim possamos fazer um prognóstico adequado frente as anomalias, positivas e negativas, responsáveis pela incidência e intensidade das secas aqui apresentadas, bem como pelas variações pluviométricas registradas ao longo dos anos, fenômeno este causador dos baixos níveis de armazenamento nos reservatórios aqui evidenciados.

\section{REFERÊNCIAS}

BRASIL. Agência Nacional das Águas. Ministério do Meio Ambiente. Conjuntura dos Recursos Hídricos no Brasil. Brasília: ANA/MMA, 2013, 432 p.: Il.

BRASIL. Agência Nacional das Águas. Ministério do Meio Ambiente. Boletim Mensais de Monitoramento: Boletim de Acompanhamento dos Reservatórios do Nordeste. Brasília: ANA/MMA, 2016a, 21 p.: Il.

BRASIL. Agência Nacional das Águas. Ministério do Meio Ambiente. Monitor de Secas do Nordeste do Brasil: dados em SIG 2012/2016. Brasília: ANA/MMA, 2016b. Disponível em: < http://monitordesecas.ana.gov.br/ >. Acesso em: 08 jul. 2016.

BRASIL. Agência Nacional das Águas. Ministério do Meio Ambiente. Sistema de Acompanhamento de Reservatórios: Nordeste e Semiárido. Brasília: ANA/MMA, 2016c. Disponível em: < http://sar.ana.gov.br/Nordeste >. Acesso em: 08 jul. 2016.

BRASIL. Serviço Geológico do Brasil. Ministério de Minas e Energia. Levantamento da Geodiversidade: projeto atlas pluviométrico do Brasil - isoietas anuais médias - período 1977 a 2006. Brasília: CPRM/MME, 2011. 1 p.: Il.

BRASIL. Instituto Brasileiro de Geografia e Estatísticas. Ministério do Planejamento, Desenvolvimento e Gestão. Portal Estados: as unidades da federação. Brasília: IBGE/MP, 2016. Disponível em: < http://www.ibge.gov.br/estadosat/ >. Acesso em: 10 jul. 2016.

GASPAR, L. Seca no Nordeste Brasileiro. Fundação Joaquim Nabuco. Recife: 2009. Disponível em: < http://basilio.fundaj.gov.br/pesquisaescolar/ >. Acesso em: 15 jul. 2016.

MARCONI, M. A; LAKATOS, E. M. Fundamentos da Metodologia Científica. 5. ed. São Paulo: Editora Atlas, 2003. 304 p.: Il.

Recebido em: 14/08/2016

Aceito para publicação em: 01/10/2016 